\title{
Adult-Onset Still's Disease in an Adult Nigerian Male - A Case Report
}

\author{
Airenakho Emorinken ${ }^{1}$, Folasade Ojuolape Agbebaku², Mercy Ofunami Dic-Ijiewere ${ }^{3}$, \\ Blessyn Omoye Akpasubi ${ }^{4}$, Asuwemhe Johnson Ugheoke ${ }^{5}$ \\ 1,2, 3, 4, 5 Department of Medicine, Irrua Specialist Teaching Hospital, Irrua, Edo State, Nigeria.
}

\section{INTRODUCTION}

Adult-Onset Still's Disease (AOSD) is an uncommon multisystemic inflammatory disease of no known aetiology. ${ }^{1}$ Bywaters in 1971 was the first to describe this clinical entity. ${ }^{2,3}$ Its estimated annual incidence is 0.16 per 100,000 persons. ${ }^{4}$ AOSD has a bimodal pattern of age distribution with peaks at $15-25$ and $36-46$ years. This shows that young adults are mainly affected. ${ }^{4}$ It is characterised by daily high spiking fever, evanescent salmon coloured rash, polyarthritis, leucocytosis, and negative immunological study. ${ }^{5}$ The rarity of the condition has led to a low index of suspicion among clinicians. Four cases of AOSD have been reported so far in Nigeria, ${ }^{6-8}$ with the first reported in 2015 by Akintayo et al. ${ }^{6}$ We report the fifth case of AOSD diagnosed at a rural tertiary facility in South-south Nigeria.

\section{PRESENTATION OF CASE}

A 42-year-old male computer engineer was referred to the accident and emergency unit of our facility with a two-month history of fever and inflammatory polyarthritis. Fever was described as high grade, intermittent, and worse in the evenings. The inflammatory polyarthritis involved the knees, elbows, shoulders, metacarpophalangeal, and wrist joints. There was a history of sore throat, fatigue, and weight loss. The patient had no skin rash, oral ulcers, genital ulcers, neck pain, or seizures. There was no ocular, urinary, respiratory, and cardiovascular symptoms.

Physical examination findings revealed a febrile patient $\left(39.5^{\circ} \mathrm{C}\right)$, with a pulse of 110 beats per minute and blood pressure of $122 / 78 \mathrm{mmHg}$. There was tenderness of the knees, wrists, elbows, and metacarpophalangeal joints. There was hepatomegaly of $6 \mathrm{cms}$ below the right subcostal margin, but no lymphadenopathy, or splenomegaly.

Laboratory investigations showed: haemoglobin 9.2 g / dL (12.0 - 18.5), leucocytosis $18.3 \times 10^{9} / \mathrm{L}$, with a predominant neutrophilia of $89 \%$, elevated liver enzymes (aspartate transaminase; AST-129 IU / L, alanine transaminase; ALT-104 IU / L), erythrocyte sedimentation rate (ESR) $130 \mathrm{~mm} / \mathrm{hr}(1-20)$, c-reactive protein $70 \mathrm{ng} / \mathrm{mL}(<5)$, serum ferritin $4500 \mathrm{ng} / \mathrm{mL}(22-112)$. Renal and coagulation profiles were normal. Thick and thin blood film for malaria parasite, serology for HIV, hepatitis B and $\mathrm{C}$, rheumatoid factor, anti-cyclic citrullinated peptide (anti-CCP), antinuclear antibody (ANA), anti-double-stranded DNA (anti-dsDNA) were all negative. Abdominal ultrasound scan, radiograph of the hand joints, peripheral blood film, and bone marrow aspiration cytology were unremarkable. Lassa fever screening, blood, and urine cultures were also negative. The absence of ANA, antidsDNA, and failure to meet the American College of Rheumatology (ACR) / European League against Rheumatism (EULAR) 2019 criteria excluded systemic lupus erythematosus. The absence of RF, anti-CCP, and non-fulfilment of ACR / EULAR 2010 classification criteria excluded rheumatoid arthritis. A haematologic malignancy was also excluded from the results of the complete blood count and negative bone marrow aspiration cytology. Sepsis was excluded from the negative septic workup.

Based on his history, examination findings, and review of laboratory results, AOSD was diagnosed applying the Yamaguchi criteria. Treatment was initiated with
Corresponding Author: Airenakho Emorinken, Department of Medicine, Irrua Specialist Teaching Hospital, Irrua, Edo State, Nigeria.

E-mail: emosairen@gmail.com

DOI: $10.14260 / j e m d s / 2021 / 210$

How to Cite This Article:

Emorinken A, Agbebaku FO, Dic-Ijiewere MO, et al. Adult-onset still's disease in an adult nigerian male: a case report. J Evolution Med Dent Sci 2021;10(13):983985, DOI: $10.14260 /$ jemds/2021/210

Submission 29-10-2020,

Peer Review 01-02-2021,

Acceptance 06-02-2021,

Published 29-03-2021.

Copyright (C) 2021 Airenakho Emorinken et al. This is an open access article distributed under Creative Commons Attribution License [Attribution 4.0 International (CC BY 4.0)] 
intravenous pulse methylprednisolone $500 \mathrm{mg}$ daily for three days, oral prednisolone, and weekly oral methotrexate $10 \mathrm{mg}$. The patient made a remarkable improvement with the rapid resolution of fever and polyarthritis. He is still been followed up.

\section{DISCUSSION}

AOSD is an uncommon multisystemic inflammatory disease of unknown aetiology. ${ }^{1}$ The postulation remains that AOSD is a reactive syndrome that results from infectious agents triggering a genetically predisposed host. ${ }^{9}$

Several infectious agents have been noted to be involved in the aetiology of AOSD; these include viruses like parvovirus, cytomegalovirus, human immunodeficiency virus, rubella virus, Epstein-Barr virus, Hepatitis $\mathrm{B}$ and $\mathrm{C}$ viruses, and bacteria like Yersinia enterocolitica, Chlamydia pneumoniae, and Mycoplasma pneumoniae.3,10,11 It has been associated with Miller-Fisher syndrome and reported to occur as a paraneoplastic syndrome. ${ }^{12,13}$

The pathogenesis of AOSD is still unclear. ${ }^{9}$ It has been reclassified as a polygenic autoinflammatory disorder over the last decade due to the recognition that its pathogenesis involves mainly the innate immune system. ${ }^{14}$ Regarding the pathogenesis of AOSD, the possible role of T-helper (Th) cells has been postulated and no familial trend has been described. 3,15

The hallmark of the pathogenesis of AOSD is macrophage and neutrophil activation. ${ }^{16}$ This is mediated by cytokines, mainly tumour necrosis factor-alpha (TNF- $\alpha$ ), interleukin (IL) 1 family (IL-1 $\beta$ and IL-18) IL-6, and IL-8.,37

Patients with AOSD typically present with fever (usually > $39^{\circ} \mathrm{C}$ ), evanescent salmon coloured rash, and polyarthritis. 13,11 Sore throat, lymphadenopathy, splenomegaly, hepatomegaly are frequently seen. The patients often present with anaemia of chronic disease, raised ESR, leucocytosis with marked neutrophilia, and thrombocytosis. ${ }^{18}$

The serum ferritin is markedly elevated in about $70 \%$ of patients with AOSD and this correlates with disease activity. ${ }^{19}$ However, there is a decrease in the proportion of glycosylated ferritin. The liver enzymes and proinflammatory cytokines may also be elevated. Macrophage activation syndrome takes place in a small group of patients with AOSD however, it may be underreported. ${ }^{20}$ Other complications include disseminated intravascular coagulopathy, alveolar haemorrhage, liver failure, myocarditis, and thrombotic thrombocytopenic purpura. ${ }^{3,17}$

Radiographs of affected joints may show joint space narrowing and erosions but carpal ankylosis is highly specific to AOSD. ${ }^{21}$ However, the radiograph of the index patient was essentially normal.

There is no specific diagnostic test for AOSD. Several sets of classification or diagnostic criteria have been suggested, including the Yamaguchi and Fautrel criteria. ${ }^{22,23}$ The Yamaguchi criteria (Table 1) is the most validated and widely accepted diagnostic criteria for AOSD diagnosis. ${ }^{24}$ In order to establish a diagnosis of AOSD, five or more criteria with at least two major must be met, after excluding infections, malignancies, or other rheumatic diseases. ${ }^{10,22}$

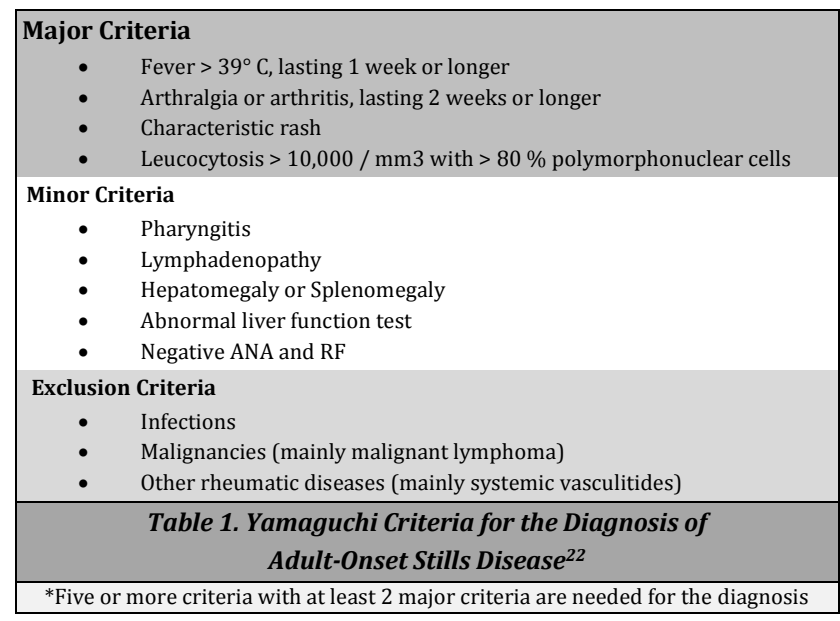

It has a sensitivity and specificity of 0.96 and 0.92 . Our patient fulfilled three major and four minor criteria. The exclusion of other potential diagnoses may make diagnosis difficult especially in Sub-Saharan Africa and other poor resource settings due to the financial implication involved in investigating the patients. ${ }^{25}$ The diagnosis of AOSD should be considered in patients with pyrexia of unknown origin.5,26

Treatment of AOSD includes the use of non-steroidal antiinflammatory drugs (NSAIDs), corticosteroids, and a combination of disease-modifying anti-rheumatic drugs.1,3,27 Biologics like anti-IL-1 (anakinra), anti-IL-6 (tocilizumab), anti-TNF $\alpha$ (etanercept), and abatacept have been used to treat refractory and complicated cases. 3,15,17,18 Therapies such as ciclosporin A and intravenous immunoglobulin have also been used. ${ }^{18}$ Our patient had glucocorticoid and methotrexate therapy with significant improvement in symptoms.

\section{CONCLUSIONS}

AOSD is an uncommon systemic chronic inflammatory disorder with no known aetiology. The diagnosis requires a high index of suspicion and other potential diagnoses should be excluded. Early diagnosis and treatment of the disease lead to a favourable prognosis and prevents complications.

Financial or other competing interests: None.

Disclosure forms provided by the authors are available with the full text of this article at jemds.com.

\section{REFERENCES}

[1] Fautrel B. Adult-onset still disease. Best Pract Res Clin Rheumatol 2008;22(5):773-92.

[2] Bywaters EG. Still's disease in the adult. Ann Rheum Dis 1971;30(2):121-33.

[3] Fong WS, Lui NL. Adult-onset still's disease: a review. Proc Singapore Healthc 2013;22(1):40-7.

[4] Magadur-Joly G, Billaud E, Barrier JH, et al. Epidemiology of adult still's disease: estimate of the incidence by a retrospective study in West France. Ann Rheum Dis 1995;54(7):587-90.

[5] Diogo M, Soares J, Pimentel T, et al. Adult-onset still disease as the cause of fever of unknown origin. Acta Med Port 2010;23(5):927-30. 
[6] Akintayo R0, Adelowo 0. Adult-onset still's disease in a Nigerian woman. BMJ Case Rep 2015;2015:bcr2015210789.

[7] Ohagwu KA, Aigbokhan EE, Olaosebikhan BH, et al. Adultonset still's disease; a rare disease in Nigeria? African Journal of Rheumatology 2016;4(1):28-30.

[8] Abbey BO, Altraide DD, Otike-Odibi BI. Adult onset still's disease: a rare disorder. Int J Res Med Sci 2018;6(8):28415.

[9] Wang MY, Jia JC, Yang CD, et al. Pathogenesis, disease course and prognosis of adult-onset still's disease: an update and review. Chin Med J (Engl) 2019;132(23):285664.

[10] Senthilvel E, Papadakis A, McNamara M, et al. Adult-onset still disease (AOSD). J Am Board Fam Med 2010;23(3):41822.

[11] Colebunders R, Stevens WJ, Vanagt E, et al. Adult still's disease caused by yersinia enterocolitica infection. Arch Intern Med 1984;144(9):1880-2.

[12] Desai SS, Allen E, Deodhar A. Miller fisher syndrome in adult onset still's disease: case report and review of the literature of other neurological manifestations. Rheumatology (Oxford) 2002;41(2):216-22.

[13] Yilmaz S, Karakas A, Cinar M, et al. Adult onset still's disease as a paraneoplastic syndrome--a case report and review of the literature. Bull Hosp Jt Dis (2013) 2013;71(2):156-60.

[14] Kastner DL, Aksentijevich I, Goldbach-Mansky R. Autoinflammatory disease reloaded: a clinical perspective. Cell 2010;140(6):784-90.

[15] Ostrowski RA, Tehrani R, Kadanoff R. Refractory adultonset still disease successfully treated with abatacept. J Clin Rheumatol 2011;17(6):315-7.

[16] Gerfaud-Valentin M, Jamilloux Y, Iwaz J, et al. Adult-onset still's disease. Autoimmun Rev 2014;13(7):708-22.
[17] Jamilloux Y, Gerfaud-Valentin M, Henry T, et al. Treatment of adult-onset still's disease: a review. Ther Clin Risk Manag 2015;11:33-43.

[18] Hamidou M, Boutoille D, Masseau A, et al. Adult-onset still disease with hemophagocytic syndrome treated with cyclosporine. Press Med 2005;34(21):1634-6.

[19] Ohta A, Yamaguchi M, Kaneoka H, et al. Adult still's disease: review of 228 cases from the literature. J Rheumatol 1988;14(6):1139-46.

[20] Hot A, Toh ML, Coppéré B, et al. Reactive Hemophagocytic syndrome in adult-onset still disease: clinical features and long-term outcome: a case-control study of 8 patients. Medicine (Baltimore) 2010;89(1):37-46.

[21] Appenzeller S, Castro GRW, Costallat LTL, et al. Adult-onset still disease in Southeast Brazil. J Clin Rheumatol 2005;11(2):76-80.

[22] Yamaguchi M, Ohta A, Tsunematsu T, et al. Preliminary criteria for classification of adult still's disease. J Rheumatol1992;19(3):424-30.

[23] Fautrel B, Zing E, Golmard JL, et al. Proposal for a new set of classification criteria for adult-onset still disease. Medicine (Baltimore) 2002;81(3):194-200.

[24] Masson C, Loët XL, Lioté F, et al. Comparative study of 6 types of criteria in adult still's disease. J Rheumatol 1996;23(3):495-7.

[25] Iba Ba J, Nzenze JR, Moubamba F, et al. Still disease in subSaharan Africa: Report of four cases in Gabon. Santé 2011;21(2):97-101.

[26] Carreño MA, Carvallo A, Trejo C, et al. Adult still's disease. A great simulator. Retrospective review of 20 patients. Rev Med Chil 2009;137(8):1010-6.

[27] Giacomelli R, Ruscitti P, Shoenfeld Y. A comprehensive review on adult onset still's disease. J Autoimmun 2018;93:24-36. 